\section{Spreading cortical depression and the maternal behavior of guinea pigs*}

\author{
JEFFREY J. STERN and LAURA SIEPIERSKI \\ University of Michigan, Dearborn, Mich. 48128
}

Female guinea pigs and their young were observed for $9 \mathrm{~h}$ over Days $2-26$ postpartum. Prior to $50 \%$ of the observation periods, the females had $20 \% \mathrm{KCl}$ applied to the neocortex through double cannulae. The results show that cortical deactivation does not modify the female's nursing time, responsiveness to its offspring, or weight gain of the piglets.

The limbic system has been implicated in the control of innate species-specific behavior (MacLean, 1957). Stamm (1955), Wilsoncroft (1962), and Slotnick (1964) all report disturbances in the maternal behavior of rats following lesions in the system. Stamm (1955), for example, reports that lesions in the cingulate and retrosplenial cortex produce disturbances in nest building, retrieval of pups, and removal of pups and nest from aversive stimuli (heat, draft from a fan). The neocortex has also been involved in the control of maternal behavior. Beach (1937) and Stone (1938) report that neocortical lesions disrupt rat maternal behavior; in general, the larger the lesion, the greater the deficit.

The present study examines further the changes in maternal behavior following loss of cortical tissue. More specifically, the study examines the effects of spreading cortical depression (Leảo, 1944) on the maternal behavior of guinea pigs.

\section{MAINTENANCE}

The Ss were nine primiparous guinea pigs from a genetically heterogeneous stock reared in our laboratory. On the day of parturition, the females ranged in age from 9 to 14 months. Guinea pig chow and water were always available. The females were housed individually in metal cages ( $16 \times 24$ in.). The laboratory was on a natural light cycle with testing taking place from August 15 to November 22, 1970.

\section{PROCEDURE}

Approximately 10 weeks prior to testing, each female had a sexually active male placed in its home cage. Of 15 guinea pigs paired, 11 became pregnant and had offspring. Two to 5 weeks following pairing, the females, under pentobarbital anesthesia supplemented with ether and atropine sulphate (1/100 grain), had double cannulae implanted bilaterally. The

* The research was funded by a Horace $H$. Rackham School of Graduate Studies grant to J. J. Stern. cannulae rested on the dura overlying the occipital-parietal region of the neocortex. The outer tube of each cannula was a 22-ga hypodermic needle, $1.2 \mathrm{~mm}$ long; the removable inner tube was a 27 -ga needle, $1.9 \mathrm{~mm}$ long and bent into a right angle. The cannulae were secured to the skull with acrylic resin.

Following 6.7 weeks of On the day of birth (Day 1), females with three or four offspring had their litter sizes reduced to two; litter size has been shown to be a factor in the control of guinea pig nursing behavior (Stern \& Bronner, 1970). Two females had only one pup each and were eliminated from study.

Starting on Day 2 and every 3 days thereafter until Day 26, the females and their offspring were observed in their home cages for $1 \mathrm{~h}$. On Day 2, five females had $20 \% \mathrm{KCl}$ placed in their cannulae, while four females had saline applied to the neocortex; the applications were reversed for each subsequent observation period. By Day 26, therefore, each female had been observed for a total of $9 \mathrm{~h}$, every other time with $\mathrm{KCl}$. The cannulae were filled $10 \mathrm{~min}$ prior to observation; the E did not know which females had been given $\mathrm{KCl}$ or saline.

During each observation period, the $E$ recorded total nursing time and the number of positive and negative responses. A positive response is defined as any behavior by the female that increases the likelihood of nursing. For example, the act of standing upright giving the pups access to the teats is scored as positive. A negative response is defined as any behavior that terminates or reduces the probability of nursing. If the piglets are nursing at the start of an observation period and the female walks away, it will have a positive score of 0 and a negative score of 1 . An approach by the pups to which the female does not actively respond is not scored, even if it leads to nursing. Finally, on Day 1 and every 3 days thereafter until Day 25, the piglets cohabitation, the males were removed. were weighed.

In order to determine whether the application of $\mathrm{KCl}$ was indeed producing spreading cortical depression, four of the females were tested in an open field following completion of the experiment. Cortical deactivation is known to reduce general locomotion activity (Grossman, 1967). The field was made of wood, measured $4 \times 4 \mathrm{ft}$, and had 16 grids on the floor. Prior to testing, each female was given a minimum of $3 \mathrm{~h}$ exposure to the field. The females were given two $10-\mathrm{min}$ sessions in the field, one time with saline and one time with $20 \% \mathrm{KCl}$. During each session, the number of grids crossed was recorded.

\section{RESULTS}

Temporary cortical deactivation did not limit nursing time in guinea pigs. If the data are divided into halves ( $\mathrm{KCl}$ vs saline), there are no significant differences for the nine females as a whole or for the animals taken individually. The statistics employed were Wilcoxon $\mathrm{z}$ tests for matched samples. Figure 1 shows the percentages of nursing time under the two conditions for the $9 \mathrm{~h}$ of observation.

Table 1 shows the mean number of positive and negative responses exhibited by the females. There was a decrease in positive and an increase in negative responding for both conditions. In other words, the probability of a female allowing its young to suckle was independent of cortical deactivation.

Finally, spreading cortical depression did not affect the weight of the young. A comparison of the piglets in this study with the eight pups from

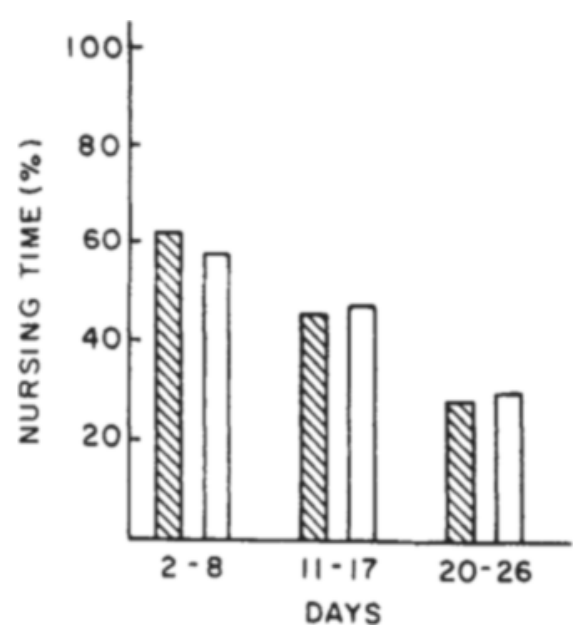

Fig. 1. Percentage of nursing time under Kcl (hatched bar) and saline (clear bar) over the days of observation. 
Table 1

Mean Number of Positive and Negative Responses (See Text for Definitions) Exhibited by the Fernales Under KC1 and Saline

Days

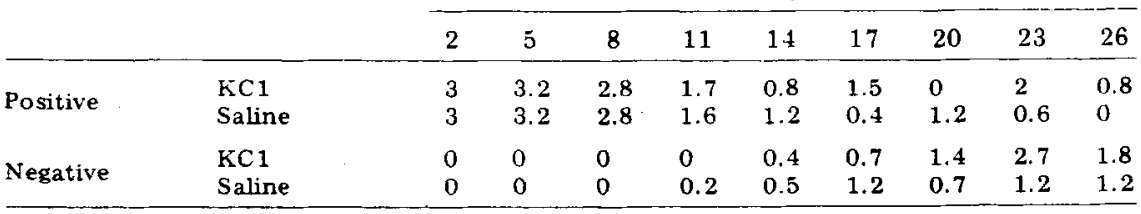

the two animal litters in a previous study (Stern, 1971) reveals no significant difference in weight (Mann-Whitney U test; Fig. 2).

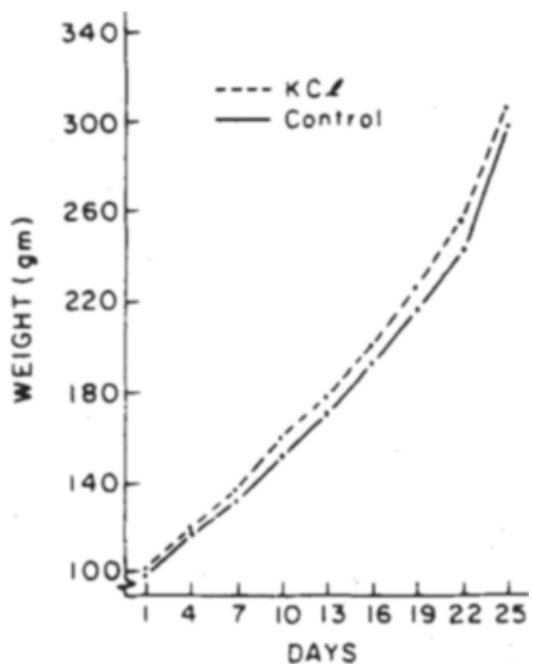

Fig. 2. Weights of the piglets in this study and those from a previous study (Stern, 1971) for Days 1-25 postpartum.
During the open-field tests with $\mathrm{KCl}$, the females crossed an average of 13.5 grids (range: 2-19); with saline, this figure was 27.0 (range: $15-43$ ) $(p<.05)$. It appears, therefore, that the application procedure was producing spreading cortical

\section{DISCUSSION}

Spreading cortical depression does not limit maternal behavior in guinea pigs. The present report demonstrates no difference between $\mathrm{KCl}$ and saline with respect to nursing time or the response of the female to its offspring. Previous work in our laboratory has shown that early social isolation of the female (Stern \& Hoffman, 1970) or ovariectomy following parturition (Stern \& Siepierski, in preparation) does not alter maternal behavior either.

Shortly after birth, piglets are ambulatory. Because of this, the typical pattern of nursing in the guinea pig is for the young to approach the mother who either permits or prevents suckling. To prevent suckling during the early days of nursing, the female simply walks away; by Week 3 the female kicks the young away. Perhaps, then, the failure of the above depression. mentioned perturbations to alter maternal behavior is due to the female's role being a passive one; the female merely allows the young to nurse. Research is presently under way to determine factors that increase the female's tendency to nurse.

\section{REFERENCES}

BEACH, F. A. The neural basis of innate behavior. I. Effects of cortical lesion upon the maternal behavior pattern in the rat. Joumal of Comparative Psychology, $1937,24,393-440$

GROSSMAN, S. P. A textbook of physiological psychology. New York: Wiley, 1967. Pp. 737.

LEẢO, A. A. P. Spreading depression of activity in the cerebral cortex. Journal of Neurophysiology, 1944, 7, 359-390.

MacLEAN. P. D. Visceral functions of the nervous system. Annuol Reliet of Physiology. Vol. 19. Palo Alto: Annual Reviews, 1957. Pp. 397-416.

SLOTNICK. B. M. Disturbances of maternal behavior in the rat following lesions of the cingulate cortex. Behaviour. 1967. $29,204-236$

STAMM, J. S. The function of the median cerebral cortex in maternal behavior of rats. Journal of Comparative \& Physiological Psychology, 1955, 48. 347-356.

STERN, J. J. Litter size and weight gain of neonatal guinea pigs. Psychological Reports, 1971, 27, 981-982.

STERN, J. J., \& BRONNER, G. Effects of litter size on nursing time and weight of the young in guinea pigs. Psychonomic Science, 1970, 21, 171-172.

STERN, J, J. HOFFMAN, B. M. Effects of social isolation until adulthood on maternal behavior in guinea pigs. Psychonomic Science, 1970, 21, 15-16.

STONE, C. P. Effects of cortical destruction on reproductive behavior and maze learning in albino rats. Journal of Comparative Psychology, 1938, 26, 217-236.

WILSONCROFT, W. E. Effects of median cortex lesions on the maternal behavior of the rat. Psychological Reports, 1963, $13,835-838$. 